\title{
SERVANT LEADERSHIP GENERASI MILENIAL DAN ZOOMERS
}

\author{
Yulita Anna \\ Program Studi Magister Manajemen FEB \\ Universitas Tanjungpura, Pontianak \\ Email korespondensi : yulita_anna@student.untan.ac.id
}

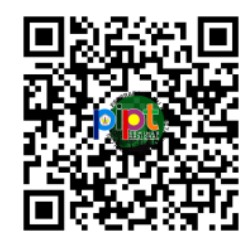

$\underline{10.26418 / \text { pipt. } 2021.38}$

\begin{abstract}
Abstrak
Generasi milenial dan zoomers saat ini telah berada pada posisi presentasi tertinggi dalam angkatan kerja di berbagai perusahaan. Di era globalisasi dengan perkembangan teknologi yang berbasis digital application dan internet of things (IOT), para generasi milenial dan zoomers sangat rentan terhadap dampak negatif kemajuan teknologi dan media sosial, namun di sisi lain generasi ini juga memberikan pengaruh yang signifikan terhadap kemajuan bangsa sehingga dibutuhkan karakter pemimpin yang sesuai untuk memimpin generasi milenial dan zoomers. Dari berbagai studi literatur, gaya servant leadership merupakan salah satu gaya kepemimpinan yang banyak diterapkan oleh beberapa perusahaan dalam memimpin para generasi milenial dan zoomers. Metode yang digunakan dalam penulisan karya ilmiah yaitu studi literatur gaya kepemimpinan servant leadership dan karakteristik generasi milenial dan zoomers 1) Mampu menjadi teladan yang baik 2) Memiliki rasa tanggung jawab 3) Berani mengambil dan bersedia mengambil risiko 4) Mempunyai sense of belonging dan sense of participation 5) Menciptakan kerjasama yang baik di kalangan rekan kerja. Generasi milenial dan zoomers akan menjadi target utama dalam berbagai program pemberdayaan peningkatan kualitas pendidikan yang selalu menanamkan karakteristik unik dari generasi milenial dan zoomers yang dapat dirangkum dalam istilah VUCA, yaitu vision (melihat ke depan), understanding (memahami), collaboration (kolaborasi) dan agility (kelincahan dan adaptif).
\end{abstract}

Kata kunci: Servant Leadership, Generasi Milenial, Generasi Zoomers, Gaya Kepemimpinan

\section{PENDAHULUAN}

Saat ini, istilah generasi milenial dan zoomers telah menjadi topik pembicaraan yang paling sering dibahas pada berbagai topik pembicaraan atau topik penulisan karya ilmiah. Kata milenial yang diciptakan oleh William Strauss dan Neil Howe dalam beberapa bukunya Millennial Generation atau generasi Y juga akrab disebut generation me atau echo boomers. Secara harfiah memang tidak ada demografi khusus dalam menentukan kelompok generasi tersebut. Namun para pakar telah menggolongkannya berdasarkan tahun awal dan tahun akhir generasi tersebut.

Generasi milenial adalah generasi yang lahir pada tahun 1980 sampai dengan 1990, sedangkan generasi zoomers adalah generasi penerus setelah generasi milenial. Generasi $\mathrm{Z}$ adalah orang yang lahir setelah 1997 yang tumbuh dengan teknologi, internet dan media sosial, sehingga generasi $\mathrm{Z}$ dikenal sebagai generasi pecandu teknologi dan cenderung anti sosial. Generasi $\mathrm{Z}$ juga seringkali disebut sebagai generasi influencer yang merupakan penduduk asli dari era digital sejati saat ini.

Banyak istilah popular tentang generasi milenial yaitu connected or digital generation atau gen why (Y) yang identik dengan karakter berani, inovatif, kreatif dan modern (Erkutlu, 2011). Alasan generasi Y disebut dengan generasi milenial karena generasi tersebut adalah generasi yang pernah melewati milenium kedua sejak teori generasi ini pertama kali dikemukakan oleh Karl Mannheim pada tahun 1923 (Kocak \& Burgaz, 2017).

Menurut paper yang dipublikasikan oleh White House, milenial memiliki tingkat pendidikan yang baik, cerdas teknologi, dan menghargai keluarga serta komunitas. Di Indonesia studi dan kajian tentang generasi milenial belum banyak dilakukan, padahal secara jumlah populasi penduduk Indonesia yang berusia antara 15-34 tahun saat ini 
sangat besar, 34,45 \% (Corinna \& Cahyono, 2019).

Mengacu pada artikel dari Nawalkha (2018), generasi milenial merasakan bahwa kerja tidak hanya sekadar mendapatkan gaji saja. Mereka menginginkan pekerjaan yang memiliki tujuan yang lebih jelas. Generasi sebelumnya bisa saja sekadar menyelesaikan pekerjaan dan mendapatkan gaji darinya. Tetapi generasi milenial menginginkan menyelesaikan pekerjaan dengan benar dan mendapatkan gaji setelah itu. Jelas terlihat bahwa generasi milenial menginginkan pekerjaan yang berbeda daripada pekerjaan sebelumnya.

Generasi $\mathrm{X}$ atau generasi baby boomers yang lahir pada tahun 1965 sampai dengan 1989an adalah generasi yang dibesarkan dalam suatu organisasi dengan struktur organisasi yang hierarkis dan struktur manajemen yang datar sehingga sistem kerja sama yang timbul di dalam organisasi berdasarkan pada tuntutan pekerjaan (Egbert \& Perez Mercader, 2016).

Generasi milenial dan zoomers memiliki harapan yang sangat berbeda tentang permasalahan ekonomi, lingkungan, kemajuan teknologi hingga persoalan sosial politik. Pada umumnya generasi milenial dan zoomers mempunyai tingkat pendidikan yang lebih baik daripada generasi $\mathrm{X}$, karena mereka telah terbiasa dengan teknologi dan juga sebagian besar dari generasi milenial mampu bekerja jauh lebih kreatif dan selalu mempunyai energi positif di berbagai bidang (Cullen et al., 1999).

Generasi zoomers atau biasanya disebut dengan generasi $\mathrm{Z}$ sekarang telah mulai meramaikan dunia kerja profesional. Badan Pusat Statistik per Agustus 2018 mencatat, bahwa ada sejumlah 4.535.480 angkatan kerja yang berusia 15-19 tahun dan 12.193.700 angkatan kerja yang berumur 2024 tahun, dimana kedua rentang usia tersebut adalah mereka yang merupakan generasi Z (Stillman dan Stillman, 2017). Terdapat sejumlah $13,5 \%$ dari keseluruhan angkatan kerja di Indonesia yang merupakan generasi Z (Badan Pusat Statistik, 2018) dan angka tersebut akan semakin meningkat ke depannya. Bencsik dan Machova (2016) menemukan bahwa generasi $\mathrm{Z}$ memiliki ciriciri yang cukup berbeda dengan generasigenerasi sebelumnya. Bahkan generasi milenial yang merupakan angkatan sebelumnya berbeda secara signifikan dengan generasi Z (Stillman dan Stillman, 2017). Generasi ini suka berkolaborasi dalam melakukan pekerjaan (Ferri-Reed, 2010), fleksibel (Renfro, 2012), tanggap terhadap tantangan dan dimotivasi oleh pencapaian (Grafton, 2011), serta suka menelaah cara yang baru dalam menyelesaikan suatu masalah (Wiedmer, 2015). Perbedaan ini memunculkan tantangan baru bagi praktik manajemen dalam organisasi.

Melalui Business 2 Community, Darleen DeRosa (2018) juga mengungkapkan bahwa semakin cepat perusahaan mulai bersiap untuk mengelola generasi $\mathrm{Z}$ maka semakin baik posisi mereka untuk bersaing di pasar tenaga kerja yang semakin kompetitif. Maka dari itu, penting bagi pemimpin organisasi untuk memahami perilaku dan kebiasaan mereka.

Setelah memahami perilaku dan kebiasaan generasi Z, diperlukan juga pemahaman akan faktor-faktor yang meningkatkan kinerja mereka. Kinerja karyawan adalah hasil kerja yang dicapai seorang pegawai yang diukur secara kuantitatif dan kualitatif dalam melaksanakan pekerjaannya sesuai dengan tanggung jawab yang diberikan kepadanya (Robbins, 2006). Knapp, Weber, \& Moellenkamp (2017) mengemukakan empat faktor yang meningkatkan kinerja karyawan generasi $\mathrm{Z}$, yaitu kohesi sosial, berbagi informasi, visi, tujuan, dan tujuan bersama, serta kepercayaan.

Studi yang dilakukan Dell Technologies pada tahun 2018 menemukan bahwa generasi $\mathrm{Z}$ sangat mementingkan interaksi antar manusia. Hubungan adalah hal yang sangat penting bagi mereka (Madden, 2017). Pernyataan ini didukung pula oleh beberapa hasil penelitian terdahulu yang menggagaskan bahwa komunikasi internal yang efektif berperan penting untuk kinerja 
karyawan (Novitasari \& Setiawan, 2015; Setyoningrum, 2017).

Komunikasi internal didefinisikan berdasarkan esensinya oleh Argenti (2003) sebagai penciptaan atmosfer saling menghormati di antara seluruh individu di dalam organisasi. Sedangkan Bovee dan Thrill (dalam Ragusa, 2010) mengartikan komunikasi internal sebagai pertukaran informasi dan gagasan di dalam organisasi. Komunikasi vertikal dan horizontal yang terjadi di antara karyawan merupakan hal yang integral yang dibutuhkan oleh setiap individu yang bekerja di perusahaan tersebut.

Rahmat (2016) mengemukakan bahwa proses kegiatan komunikasi pada sebuah organisasi memiliki peran yang penting selaku katalisator antara karyawan, karyawan dengan supervisor, begitu juga sebaliknya antara supervisor dengan karyawan. Keefektifan dari komunikasi internal memperteguh kepercayaan dari anggota perusahaan bahwa mereka adalah kekayaan yang berharga untuk perusahaan (Argenti, 2010).

Meningkatnya generasi milenial dan zoomers yang masuk dalam dunia kerja dengan keistimewaan yang cenderung berbeda dengan generasi-generasi sebelumnya menjadi salah satu tantangan baru di dunia kerja saat ini. Generasi milenial dan zoomers seringkali didefinisikan sebagai generasi yang menyukai kebebasan, fleksibel, mandiri, media sosial dan internet of thing (IOT).

Pada saat ini banyak perusahaan sedang mengalami tahap asimilasi, dimana para pemegang keputusan cenderung berasal dari generasi sebelumnya (baby boomer atau generasi X), sedangkan kebanyakan karyawan entry level merupakan generasi milenial dan zoomers. Perbedaan karakter tersebut seringkali menjadi tantangan tersendiri dalam kerja sama tim dan komunikasi harian.

Berdasarkan penelitian yang dilakukan oleh Charles (2015), servant leadership memberikan efek positif pada kepuasan karyawan terhadap pemimpinnya.
Perusahaan bergerak cepat untuk meningkatkan kepuasan kerja karyawan melalui program servant leadership yang dimulai pada tahun 2018, dengan melibatkan para level manajer inti sebagai peserta program. Namun belum ada studi yang dilakukan perusahaan untuk membuktikan efektivitas program pelatihan tersebut dalam meningkatkan kepuasan kerja terhadap karyawan. Penelitian ini penting dilakukan dalam upaya mengembangkan generasi milenial dan zoomers dengan gaya kepemimpinan servant leadership di tengah kondisi dominasi generasi milenial dan zoomers dalam suatu organisasi.

Pada era globalisasi saat ini, semakin banyak tantangan dan tuntutan teknologi dalam memaksimalkan penggunaan IOT (intenet of thing) dalam kegiatan sehari-hari dan pekerjaan di suatu organisasi. Keberadaan seorang pemimpin dalam organisasi maupun individu sangat dibutuhkan untuk membawa organisasi atau individu kepada tujuan yang telah ditetapkan oleh suatu organisasi. Servant leadership dapat menjadi pedoman bagi pemimpin dalam memimpin generasi milenial dan zoomers dalam suatu organisasi. Karakteristik generasi milenial dan zoomers mendorong tren dimana anak milenial dan zoomers sekarang lebih selektif dalam memilih pekerjaan yang sesuai, dan hal ini tidak lepas dari sikap kepemimpinan yang mereka miliki. Tahun 2020 hingga tahun 2030 diprediksikan bahwa Indonesia akan mencapai puncak populasi usia produktif sebesar 70\% dari total penduduk Indonesia (Sebastian, Amran dan Youth Lab, 2016). Hal ini bisa menjadi sebuah keunggulan bagi perekonomian dan kemajuan Indonesia apabila generasi milenial dan zoomers sebagai generasi dengan jumlah yang besar dapat dikelola dengan baik sehingga dibutuhkan karakter pemimpin yang cocok untuk generasi milenial dan zoomers (Bosscher, 2013).

Fenomena yang ditemukan saat ini adalah tujuan individu bekerja tidak hanya untuk pemenuhan kebutuhan materi saja, tetapi juga memenuhi kebutuhan lainnya 
seperti kebutuhan keterikatan sosial, perasaan dihargai oleh orang lain serta merasa kompeten dan mampu dalam menyelesaikan pekerjaan (Malvikawalia, 2016). Adanya kekurangan dalam pemberian kesempatan bagi karyawan untuk menunjukkan kemampuan yang dimiliki dan pengembangan karier di masa yang akan datang menyebabkan generasi milenial merasa kurang berkesempatan untuk mengembangkan kemampuan diri. Salah satu faktor krusial dalam pengembangan kualitas sumber daya manusia adalah kepemimpinan. Peran pemimpin dalam suatu organisasi sangat penting, karena pemimpin sangat menentukan kelangsungan hidup serta pengembangan setiap individu dalam suatu organisasi (Ancok,2012).

Servant leadership merupakan gaya kepemimpinan yang berfokus pada membantu individu untuk mengembangkan dirinya. Dengan memberikan kesempatan setiap orang untuk dapat terlibat dan memperlakukan mereka lebih manusiawi, bukan berdasarkan pada posisi dan kekuasaan yang dimiliki (Chungtai, 2016).

Berdasarkan fenomena tersebut penulis tertarik untuk membuat sebuah penulisan analisis terkait gaya kepemimpinan servant leadership bagi generasi milenial dan zoomers. Berdasarkan studi literatur karakter yang harus dimiliki oleh seorang pemimpin milenial dan zoomers: 1) Mampu menjadi teladan yang baik, 2) Memiliki rasa tanggung jawab, 3) Berani mengambil risiko, 4) Mempunyai sense of belonging dari para bawahan dan sense of participation, 5) Menciptakan kerjasama yang baik di kalangan rekan kerja yang merupakan karakter yang harus dimiliki oleh pemimpin di generasi milenial dan zoomers (Brander, Patterson, \& Chan 2012). Penelitian terdahulu yang telah dilakukan Amiroh Ambarwati dan Susilo Teguh Raharjo (2018) yang meneliti tentang prinsip kepemimpinan karakteristik pada era generasi milenial, sedangkan penelitian ini melakukan studi literatur tentang generasi milenial dan generasi zoomers dengan gaya kepemimpinan servant leadership. Pada tahun 2020, Indonesia telah memasuki era bonus demografi dimana generasi milenial dan zoomers akan memiliki populasi yang lebih banyak dari generasi sebelumnya dan berada pada usia produktif. Generasi milenial dan generasi zoomers adalah tulang punggung dari pertumbuhan perekonomian Indonesia.

Tabel 1. Data Sensus Penduduk Indonesia 2020

\begin{tabular}{|l|c|}
\hline \multicolumn{1}{|c|}{ Generasi } & Persentasi \\
\hline Generasi & $74,93 \%$ \\
Zoomers & $69,38 \%$ \\
\hline $\begin{array}{l}\text { Generasi } \\
\text { Milenial }\end{array}$ & $58,65 \%$ \\
\hline Generasi X & $31,01 \%$ \\
\hline Baby Boomer & $29,17 \%$ \\
\hline Post Gen Z & $5,03 \%$ \\
\hline Pre Boomer & \\
\hline
\end{tabular}

Sumber: (Badan Pusat Statistik (BPS), Januari 2021)

\section{METODOLOGI}

Metode yang digunakan yaitu studi literatur melalui buku, jurnal, dan berita online. Karya ilmiah ini memberikan gambaran terkait gaya kepemimpinan servant leadership pada era generasi milenial dan zoomers. Serta memberikan gambaran terkait peran pemimpin era milenial sebagai generasi penerus bangsa untuk mampu bertanggung jawab mempersiapkan masa depan dengan berperilaku adaptif, kritis, tangguh, melek terhadap teknologi informasi, realistis, dan positif untuk menciptakan generasi emas.

\section{HASIL DAN PEMBAHASAN}

Gaya kepemimpinan di era generasi milenial dan zoomers telah banyak mengalami perubahan dan memunculkan tren baru di dunia leadership. Tren yang pertama di era milenial dan zoomers yang banyak diterapkan oleh perusahaan modern saat ini adalah pendekatan gaya kepemimpinan yang bersifat customized dimana seorang pemimpin harus mampu 
mengubah gaya kepemimpinannya secara situasional sesuai kebutuhan. Fokusnya pada manusia termasuk mempertimbangkan faktor perbedaan generasi yang dipimpin. Saat ini manusia dipandang sebagai aset penting perusahaan (human capital) yang memiliki potensi layak dikembangkan, bukan lagi sebagai mesin yang menunggu diperintah di zaman revolusi industri terdahulu.

Tren perubahan kedua terlihat pada aspek kepemimpinan yang mempertimbangkan faktor lintas budaya. Saat ini banyak perusahaan lokal dan multinasional yang karyawannya berasal dari berbagai macam suku dan kewarganegaraan. Perusahaan yang sukses adalah perusahaan yang mampu beradaptasi terhadap perbedaan kultur dalam berkomunikasi dan membangun hubungan erat dengan karyawannya yang dikenal dengan istilah leading inter cultural.

Tren ketiga adalah tren yang ke depannya akan memperlihatkan semakin banyak pemimpin muda yang menempati posisi eksekutif organisasi. Sejak awal mereka telah dipacu untuk berpikir kreatif dalam mengatasi kompleksitas bisnis. Mereka tidak lagi dibiarkan untuk berpikir sendiri tetapi perusahaan akan menyediakan sarana agar mereka dapat saling berinteraksi merumuskan pemikiran baru untuk mengatasi tantangan ke depan. Ide pengembangan perusahaan tidak lagi selalu muncul dari level manajemen tertinggi di organisasi, dimana setiap orang diberikan kesempatan untuk menyalurkan ide-idenya melalui suatu sistem kolaborasi. Konsep kepemimpinan seperti ini dikenal dengan istilah distributed leadership atau shared leadership.

Berdasarkan penelitian dari Long (2017) mengenai pengaruh gaya kepemimpinan transformasional, ethical dan servant leadership terhadap motivasi generasi milenial, dapat disimpulkan bahwa ketiga gaya kepemimpinan tersebut efektif dalam memotivasi karyawan generasi milenial. Namun dari hasil studi ditemukan bahwa servant leadership memiliki hubungan paling kuat dalam memotivasi karyawan milenial.

Menurut Barbuto Jr \& Gottfredson (2016), tipe kepemimpinan servant leader secara unik cocok dalam memenuhi harapan dari generasi milenial, karena berfokus pada kebutuhan dan pengembangan bawahannya.

Pelatihan servant leadership mungkin memerlukan perubahan dalam organisasi untuk menjadi lebih fokus pada karyawan, perubahan ini diperlukan apabila organisasi ingin menarik dan menahan talenta dari generasi milenial dan zoomers. Organisasi dipercaya memiliki kemampuan dalam menarik dan menahan talenta utamanya dengan mempromosikan dan melatih pemimpin mereka untuk menjadi servant leader. Servant leader secara unik terkualifikasi untuk menarik dan menahan para milenial dan zoomers, karena apa yang dicari oleh para milenial dan zoomers sesuai dengan apa yang dapat diberikan oleh servant leader.

Hasil studi Arain et al (2019) menyatakan bahwa terlepas dari keterbatasan dalam mengimplementasikan servant leadership, konsep ini memiliki implikasi penting untuk dipraktikkan. Adanya servant leadership dapat membantu para karyawan agar lebih aktif dalam memberikan pendapatnya dan memberikan rasa keterikatan karyawan untuk terlibat dalam aktivitas organisasi walaupun berisiko. Konsep servant leadership juga dapat diaplikasikan saat rekrutmen dan promosi karyawan. Selain itu, penggunaan servant leadership oleh manajemen puncak dapat memberikan pesan positif ke para manager dan karyawannya mengenai pentingnya strategi servant leadership dalam organisasi.

Berdasarkan hasil studi Eva et al (2019), servant leadership telah menunjukkan peningkatan tingkat efektivitas pada tim, keamanan psikologis tim, dan kreativitas serta tingkat inovasi tim. Di tingkat organisasi, servant leadership telah ditemukan berhubungan positif dengan kinerja perusahaan. Servant leadership, sesuai yang dijelaskan oleh Brewer (2010), 
memiliki beberapa karakter atau dimensi penting: a) Listening adalah kemampuan mendengarkan orang lain merupakan fondasi untuk membangun hubungan dengan bawahan. Dengan mendengarkan, kita akan mendapatkan pengetahuan. Mendengarkan merupakan hal yang luar biasa, hal tersebut membuat pemimpin mendapatkan informasi dan menemukan makna terhadap apa yang disampaikan kepadanya. $\quad$ b) Empathy adalah dimulai dengan memahami bahwa pemimpin bertanggungjawab untuk mengatur kelompok yang terdiri dari berbagai individu. Servant leader, secara personal, mengetahui masing-masing bawahannya, dan memberikan apresiasi ke setiap orang yang sudah bekerja. c) Healing adalah dimana pemimpin harus menyadari bahwa hati manusia sangat rentan. Pemimpin harus memahami secara cepat setiap individu yang sedang membutuhkan pertolongan, dan mendampinginya saat proses penyembuhan. Seringkali menyakiti orang, akan berdampak dengan menyakiti orang yang lainnya lagi, dan hal ini akan mempengaruhi tujuan yang akan dicapai organisasi. d) Awareness adalah pemimpin menjadi sadar terhadap situasi organisasi, terutama dalam hal moral dan etika, akan menjadikan pemimpin menjadi lebih baik dalam menangani konflik yang ada. e) Persuasion adalah pemimpin yang otoriter membuat keputusan berdasarkan posisi dan jabatan daripada persuasi. Servant leader membangun kesepakatan yang efektif terhadap kelompoknya dengan tujuan untuk membawa perubahan. Kemampuan meyakinkan orang lain merupakan fondasi dari kerja sama tim. f) Foresight adalah kemampuan yang dipelajari dari kesalahan masa lalu, dan muncul dari sebuah kegagalan. Foresight mencegah untuk mengulangi kesalahan yang sama. g) Stewardship adalah kesadaran diri untuk ikut bertanggungjawab terhadap kesuksesan maupun kegagalan organisasi. Stewardship seperti melayani orang lain, komitmen untuk memenuhi kebutuhan orang lain. h) Komitmen adalah pemimpin harus berkomitmen untuk pengembangan karyawan. Servant leader memahami kedinamisan dalam pembagian tanggungjawab dan delegasi. Pemimpin memahami kelebihan dan kelemahan karyawannya, dan memberikan tugas sesuai kelebihan masing-masing karyawannya. Servant leader berkontribusi dalam memberikan sumber daya yang dibutuhkan untuk pengembangan karier karyawannya. i) Building community adalah komunitas yang merupakan cerminan dari karyawan sebuah organisasi, dan servant leader diharapkan dapat menjangkau lebih luas dari batasan institusi.

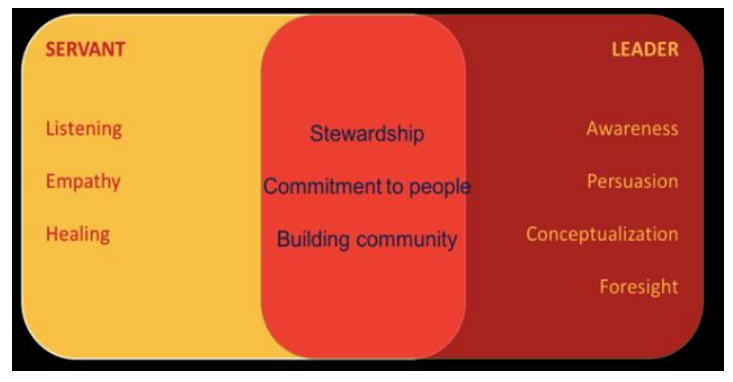

Source: (The Servant Leadership Book, Greenleaf, 1970)

Gambar 1. Karakteristik Servant Leadership

Menurut Savage-Austin \& Honeycutt (2011), praktik servant leadership secara mendalam akan mempengaruhi organisasi secara alami, diantaranya komunikasi terbuka antar satu dengan yang lain, pertukaran informasi, peningkatan loyalitas antara pimpinan dan anggota organisasi. Keuntungan tambahan dalam mengadopsi filosofi servant leadership termasuk perbaikan dalam proses pengambilan keputusan, peningkatan produktivitas, peningkatan aspek moral dan pengurangan turnover karyawan. Penghambat praktik servant leadership yang lazim ditemukan yakni terkait budaya perusahaan, ketakutan adanya perubahan, kurangnya pengetahuan mengenai filosofi praktik servant leadership. Setiap generasi membutuhkan pemimpin dan karakter yang berbeda beda. Khusus untuk menjadi pemimpin untuk generasi milenial harus memiliki karakteristik: 1) Mampu menjadi teladan yang baik, yaitu setiap manusia dalam suatu generasi adalah pemimpin yang harus siap untuk memimpin 
apa dan siapa yang pimpin. Hanya saja posisi atau status turut menentukan sebesar apa tanggungjawab kita sebagai pemimpin. Ada satu hal penting yang cukup menarik mengenai konsep kepemimpinan untuk masyarakat milenial dan zoomers yakni kepemimpinan itu merupakan suatu karakter dari seorang pemimpin dimana salah satunya harus menjadi teladan bagi orang lain atau bagi masyarakat yang dipimpinnya. Layaknya posisi seorang ibu dan ayah bagi anak dalam lingkungan keluarga, maka seorang pemimpin juga seolah menjadi orang tua bagi masyarakat yang dipimpinnya, masyarakat milenial tersebut pada akhirnya akan mencontoh apa yang dilakukan oleh pemimpin. Maka sebagai seorang pemimpin untuk era milenial dan zoomers, selain harus mempunyai jiwa kepemimpinan yang baik, mempunyai kapasitas dan kapabilitas dalam memimpin sehingga bisa menciptakan kondisi yang efektif, efisien dan produktif, juga seorang pemimpin milenial harus mampu mempunyai karakter atau attitude yang baik sehingga ia menjadi teladan bagi rakyatnya. Segala tindak tanduk pemimpin akan menjadi penilaian bagi masyarakatnya, baik itu tindakannya sebagai pemimpin suatu lembaga atau dalam hal tindakan ia sebagai masyarakat biasa termasuk dalam ranah sosialisasi dengan masyarakatnya (Huffman, 2015). Hasilnya selain masyarakat yang tidak mendapatkan contoh yang baik dari pemimpinnya, juga muncul ketidakpercayaan dari rakyat kepada pemerintah yang tentunya hal ini sangat merugikan dalam proses pemerintahan di negara tersebut. Maka dari itu sebagai seorang pemimpin, sudah seharusnya dapat membangun sikap yang baik agar menjadi teladan bagi siapa nanti yang kita pimpin, sehingga terbangun masyarakat yang baik dan menciptakan efektifitas dalam pembangunan dengan harapan adanya antusias yang besar dari rakyat milenial terhadap pemimpinnya (Wu, Tang, Dong, \& Liu, 2015).

2) Mempunyai rasa tanggung jawab, yaitu manusia adalah makhluk sosial yang menjadi pemimpin bagi dirinya sendiri dan menjadi pemimpin bagi orang lain. Menjadi pemimpin berarti menjadi seseorang yang memiliki tanggung jawab lebih dalam hidup. Ada ungkapan dari Warren G. Bennis seorang pelopor studi kepemimpinan kontemporer mengatakan bahwa mitos kepemimpinan yang paling berbahaya adalah "bahwa pemimpin dilahirkan, bahwa ada faktor genetik yang untuk kepemimpinan. Itu hanya omong kosong yang pada kenyataannya kebenarannya adalah sebaliknya. Pemimpin sendiri bukan dari bawaan lahir melainkan diciptakan dan disiapkan (Bell, 2015). Pemimpin adalah seseorang yang menggunakan kemampuannya, sikapnya, nalurinya, dan ciri-ciri kepribadiannya yang mampu menciptakan suatu keadaan, sehingga orang lain yang dipimpinnya dapat saling bekerja sama untuk mencapai tujuan. Seorang pemimpin dengan melaksanakan tugas berdasarkan prinsip dasar manajemen, yaitu perencanaan, pengorganisasian, pelaksanaan dan pengendalian sehingga mampu menciptakan keadaan orang lain yang dipimpinnya saling bekerja sama untuk mencapai tujuan. Selain itu pemimpin harus mempunyai kreativitas yang tinggi (Ali \& Waqar, 2013). Pemimpin yang ideal salah satunya pemimpin yang bertanggung jawab. Bertanggung jawab berarti berani untuk menanggung efek dari segala keputusan yang timbul akibat tindakan yang telah dilaksanakan. Selain cerdas dan berinisiatif, seorang pemimpin yang ideal tentunya perlu memiliki sifat bertanggung jawab. Pengambilan keputusan terhadap cara kerja dan pelaksanaan misi suatu kelompok tentunya diputuskan dengan tidak tergesagesa (Setyaningrum, 2017). Dalam pengambilan keputusan, pemimpin harus menjadi seorang pendengar yang baik. Sebagai pemimpin, tidak langsung memberikan solusi melainkan fokus untuk membimbing dan menasihati agar orang itu sendirilah yang menemukan solusi tersebut dan menjalaninya. Dalam menemukan solusi tersebut harus keluar dari out of the box, dan selalu memiliki pandangan jauh ke depan 
serta memiliki pengetahuan yang luas, sehingga bisa diandalkan untuk memberikan solusi (S. J. Lambert, 2000). Maka, pemimpin yang bertanggung jawab adalah pemimpin yang tetap teguh dan mampu berpikir taktis untuk menerima segala risiko yang timbul dari keputusan yang diambil. Pemimpin selalu berjiwa besar, menerima kritik dan selalu mengambil tanggung jawab atas semua keputusan yang ia ambil. Serta tidak pernah mencari kambing hitam atau menyalahkan orang di sekitarnya (Chullen, Dunford, Angermeier, Boss, \& Boss, 2010).

3) Berani mengambil risiko, yaitu dalam diri seseorang terdapat sebuah mental yang ada pada diri masing-masing, dan tahukah anda kalau mental adalah sebuah kunci keberhasilan dari individu tersebut, jika pada individu mempunyai mental yang kuat maka presentasi dari tingkat keberhasilannya akan besar, hal ini dikarenakan bahwa mental sangat mempengaruhi seseorang dalam mengambil keputusan sehingga jika seorang individu tersebut mempunyai mental yang cukup besar maka individu tersebut dapat memutuskan suatu keputusan dengan cepat sehingga dia akan lebih cepat untuk mengetahui apakah keputusannya tersebut adalah hal yang baik atau buruk. Di sinilah kita mendapatkan pembelajaran dari sebuah keputusan kita sendiri, sehingga kita akan cepat tumbuh menjadi seorang yang dewasa dan mempunyai pengalaman untuk menjadi seorang yang lebih baik, karena jika seorang individu tersebut dalam mengambil keputusan yang lambat maka dia akan lambat tumbuh dewasa dan akan lambat menjadi seorang yang baik karena ketangkasan dalam mengambil keputusan memerlukan kecepatan berfikir dan berani mengambil risiko dengan berbagai konsekuensinya (Khan, Salleh, \& Hemdi, 2016). Konsekuensi apapun yang akan kita dapatkan dari sebuah keputusan, haruslah kita menyikapi dengan positif karena hal itu dapat menjadi pemacu kehidupan kita dalam membangun integritas diri dan menyikapi suatu masalah, hal inilah yang dialami oleh para pemimpin bangsa kita yaitu keterlambatan dalam menyikapi masalah sehingga menyebabkan lambatnya negara kita dalam berkembang dikarenakan lambatnya sang pemimpin dalam menyikapi sebuah masalah dan ketidakberaniannya pemimpin kita dalam mengambil risiko sehingga mengorbankan kedewasaan negara kita sendiri dan berakibatkan pada perekonomian negara (Choi, 2014).

4) Sense of belonging (merasa ikut memiliki), sense of participation (merasa ikut serta) dan sense of responsibility (merasa ikut bertanggung jawab). Dalam sebuah perkumpulan tidak akan terlepas dari sosok seorang leaders, mulai dari perkumpulan sederhana sampai organisasi besar peran pemimpin sangat vital. Maju mundurnya sebuah organisasi sangat tergantung dari seorang leaders. Pemimpin adalah sosok yang sangat berperan dalam menakhodai sebuah organisasi. Tetapi sehebat apapun kepemimpinan seseorang tanpa didukung dengan manajemen tim yang bagus akan percuma, jadi kesolidan sebuah organisasi juga sangat penting agar organisasi itu bisa terus melaju sesuai dengan cita-citanya. pemimpin mempunyai tanggung jawab memastikan setiap anggotanya bekerja dengan baik, pemimpin juga harus memastikan program-program kerja berjalan. Selain itu seorang pemimpin juga harus mempunyai kepekaan sosial yang tinggi, pemimpin tidak bisa bertindak semena-mena menyuruh ini itu, tanpa melihat kondisi lapangan atau anggota. Pemimpin harus tegas tetapi juga harus bijak dalam mengambil setiap keputusan. pemimpin yang tidak kreatif adalah pemimpin yang gagal, karena seharusnya pemimpin harus memunculkan inovasiinovasi dalam setiap gagasannya, memunculkan hal- hal baru dengan gagasangagasan yang spektakuler, beda dengan yang lainnya. pemimpin bukan mereka yang hanya menerima mandat lalu menjalankan tugas kalau seperti ini bukan pemimpin tetapi PLT (Dillard, Hale, \& Segrin, 1994). Pemimpin harus punya program dan harus berani mengambil setiap keputusan. Pemimpin juga harus bisa menyemai kekompakan, memelihara loyalitas setiap 
anggota, memastikan anggota loyal padanya. bukan berarti ia seorang yang otoriter, tetapi memang setiap anggota harus berada dalam jalur visi misi seorang pemimpin kalau tidak, maka akan menjadi benalu bagi kepemimpinannya. Pemimpin yang baik harus bertanggung jawab terhadap semua kegiatan yang menjadi programnya dan tidak selalu merasa paling benar, tetapi pemimpin yang baik adalah orang yang selalu menerima masukan dari anggotaanggota mempertimbangkannya dan mengambil keputusan dengan musyawarah. Selain itu seorang pemimpin ialah motivator, pemimpin harus mampu memberi motivasi kepada anggota- anggotanya, agar mereka menjalankan tugas-tugasnya dengan penuh semangat dan penuh dedikasi dan tanggung jawab. Dan pemimpin yang baik itu ia yang tidak segan memberi pujian penghargaan kepada anggotanya (Shang, Huang, \& Guo, 2010).

5) Menciptakan kerja sama yang baik di kalangan anggota, yaitu dalam suatu organisasi atau perusahaan, untuk mencapai tujuan bersama diperlukan suatu kerja sama dari anggota-anggota yang ada di dalamnya. Pentingnya menjalin kerja sama dalam organisasi akan berdampak positif terhadap kinerja yang efektif. Salah satu hal yang mengawali lahirnya kerja sama adalah jalinan komunikasi yang baik. Komunikasi merupakan hal terpenting dalam keberhasilan suatu organisasi atau perusahaan. Jika anggota dalam perusahaan tersebut menjalin komunikasi dengan baik maka perusahaan tersebut mempunyai peluang besar untuk meraih keberhasilan (Lu et al., 2010). Terbentuknya komunikasi yang mengawali kerja sama tim dalam perusahaan, tidak semudah dilaksanakan. Kesuksesan perusahaan yang didasari kemampuan para anggota untuk bekerja sama ditentukan oleh komunikasi yang baik. Oleh karena itu, setiap perusahaan mempunyai kewajiban untuk mengembangkan komunikasi dari berbagai pihak, baik itu antara pemimpin, anggota, dan masyarakat di sekitar lingkungan kerja agar dapat membantu mewujudkan kerja sama tim yang baik (Mangi, n.d.). Menjadi seorang pemimpin yang baik pada generasi masyarakat milenial saat ini dan ke depan menjadi satu tantangan yang kritis. Banyak pendapat yang mengatakan bahwa kepemimpinan merupakan karakter sejak lahir.

Pemimpin juga harus memiliki sifat berani mengambil keputusan yang terbaik untuk kepentingan rakyat atau golongannya. Yang terpenting dari semua karakter tersebut seorang pemimpin harus memiliki sifat jujur, karena ketidakjujuran bisa merusak sendi-sendi dalam berbangsa dan bernegara. Ketidakjujuran adalah sebuah penyakit yang sangat sulit diobati. Sekali melakukan kebohongan akan menuntut ketidakjujuran berikutnya (Kamani \& Namdari, 2012).

Sebagai bangsa yang besar dan semakin diperhitungkan di kancah internasional, Indonesia memiliki banyak tantangan yang harus diselesaikan. Membangun Indonesia berarti membangun mental rakyatnya sehingga gagasan revolusi mental pun lahir dan dicetuskan pemerintah sebagai gerakan yang masif. Untuk proses perubahan besar itu, kepemimpinan model lama tidak akan cocok lagi dan oleh karena itu harus dikoreksi atau dikembangkan. Dengan generasi muda di Indonesia yang tumbuh begitu pesat, maka gaya kepemimpinan yang muncul pun harus menyesuaikan ritme dan polanya. Generasi milenial yang saat ini memengaruhi banyak hal juga harus dipimpin dengan gaya kepemimpinan milenial (E. G. Lambert, Hogan, Dial, Altheimer, \& Barton-Bellessa, 2012).

Kepemimpinan milenial dan zoomer ini penulis terjemahkan sebagai kepemimpinan masa kini yang menyesuaikan dengan gaya generasi baru yang lahir di era 1980-an. Pola kepemimpinan milenial tidak sama dengan pola kepemimpinan lama dari generasi sebelumnya. Tahun kelahiran 1980-an itu penting karena generasi tersebut saat ini memasuki masa paling produktif.

Beberapa karakter generasi milenial dan zoomers ini adalah, pertama kemampuan mereka mengakses teknologi informasi yang lebih baik dari generasi sebelumnya. Media 
sosial menjadi bagian kehidupan mereka sehari-hari. Internet pun menjadi sumber informasi dan pengetahuan bagi mereka. Apa pun kebutuhan informasi yang mereka perlukan, sebagian besar mereka peroleh dari internet dan media sosial.

Kedua, generasi milenial dan zoomers lebih memiliki keberanian dalam berinovasi. Mereka lebih termotivasi menciptakan startup atau merintis usaha dan bisnis baru. Karena itu merupakan bagian dari tantangan yang membuat adrenalin mereka mengalir.

Ketiga, generasi milenial dan zoomers lebih menyukai independensi dan kemandirian. Independensi ini merupakan kebutuhan yang lahir dari gaya hidup yang ingin lebih bebas dan mandiri dalam melakukan sesuatu.

Keempat, generasi milenial dan zoomers lebih menyukai sesuatu yang instan. Mungkin ciri ini bisa dipersepsikan secara positif atau negatif. Positifnya, generasi ini menyukai sesuatu yang praktis dan simpel. Negatifnya, generasi ini mungkin memiliki daya tahan yang lebih rendah terhadap tekanan dan stres karena terbiasa melakukan sesuatu dengan cepat dan instan sehingga kurang sabar jika hasil yang diperoleh tidak muncul seketika.

Dengan memahami karakter generasi milenial dan zoomers ini, kepemimpinan yang muncul pun perlu menjadi bagian dari figur yang cocok dengan mereka. Penerjemahan tentang kepemimpinan milenial dan zoomers ini pun fleksibel dan belum ada definisi mutlak dari para pakar kepemimpinan (Shanker, 2016). Meski demikian, beberapa yang dapat ditekankan dalam pola kepemimpinan ini antara lain, pertama, kepemimpinan milenial dan zoomers perlu memahami dan memakai pola komunikasi generasi milenial dan zoomers yang dipimpinnya. Misalnya pemimpin milenial dan zoomers tidak segan menggunakan media sosial seperti Twitter, Facebook, Instagram, YouTube, Tik Tok, dan saluran komunikasi terbaru yang memang menjadi arus utama dalam kehidupan generasi baru itu.
Kedua, kepemimpinan milenial dan zoomers perlu mendorong inovasi, kreativitas, dan jiwa entrepreneurship generasi baru itu. Semua saluran inovasi, kreativitas dan entrepreneurship harus dirancang dengan baik dan kongkrit. Jangan hanya berisi wacana saja, tapi bangunlah proses yang benar-benar dapat dinikmati oleh generasi milenial dan zoomers ini mengembangkan dirinya. Misalnya pemimpin milenial dan zoomers perlu membangun pusat kreativitas di setiap kota. Dengan membangun sebanyak mungkin workshop dengan peralatan dan teknologi terbaru seperti zoom meeting, google meet, webex, Instagram Live, Tik Tok, You Tube dan platform online lainnya. Biarkan gagasan dan ide generasi milenial dan zoomers dapat tersalurkan.

Ketiga, kepemimpinan milenial dan zoomers perlu mendukung kemandirian dan jiwa entrepreneurship generasi milenial dan zoomers. Kesalahan pola pendidikan pada generasi lama ialah kemandirian dan jiwa entrepreneurship mereka tidak dibangun secara kokoh sejak dini. Pendidikan kemandirian dan entrepreneurship ini penting bagi masa depan bangsa dan negara untuk bersaing dengan bangsa-bangsa lain yang selama ini mendominasi berbagai bidang dan industri. Kepemimpinan milenial dan zoomers harus menyadari poin penting ini dalam membangun mental generasi baru (Yoon, Jang, \& Lee, 2016).

Dengan menggabungkan antara pola kepemimpinan milenial, zoomers dan revolusi mental, konsep baru ini diharapkan memiliki daya dorong yang kuat pada upaya memajukan bangsa. Ketika konsep ini benar-benar diterapkan di berbagai wilayah di Indonesia maka hasil konkretnya dapat terlihat dari munculnya generasi milenial dan zoomers yang tangguh, mandiri, inovatif, dan kreatif. Generasi milenial dan generasi zoomers yang akan membuat bangsa ini dapat bersaing dan bertahan dalam persaingan internasional (Altuntas \& Baykal, 2010).

\section{KESIMPULAN}


Pada tahun 2030 sampai dengan 2040, Indonesia telah diprediksi akan mengalami masa bonus demografi, dimana jumlah penduduk usia produktif (berusia 15-64 tahun) lebih besar dibandingkan penduduk usia tidak produktif (berusia di bawah 15 tahun dan di atas 64 tahun). Dengan kata lain generasi milenial (Y) dan generasi zoomers (Z) pada tahun 2030 akan mencapai usia puncaknya. Generasi inilah yang akan menjadi para calon pemimpin di masa yang akan datang dan yang memegang kendali atas perekonomian Indonesia dan diharapkan mampu untuk membawa bangsa Indonesia menuju arah pembangunan yang lebih maju serta dinamis mengikuti perkembangan teknologi serba internet of thing (IOT). Generasi milenial dan zoomers akan menjadi target utama dalam berbagai program pemberdayaan peningkatan kualitas pendidikan yang selalu menanamkan karakteristik unik dari generasi milenial dan zoomers yang dapat dirangkum dalam istilah VUCA, yaitu vision (melihat ke depan), understanding (memahami), collaboration (kolaborasi) dan agility (kelincahan dan adaptif).

\section{UCAPAN TERIMA KASIH}

Peneliti menyampaikan terima kasih kepada dosen pembimbing Bpk. Dr. M. Irfani Hendri, SE, M.Si dan Bpk. Candra Wijaya ST, MBA selaku Assistant Vice President BCA yang sudah bersedia membimbing dan mendukung saya dalam melakukan proses penulisan penelitian.

\section{DAFTAR PUSTAKA}

Alafeshat R, Aboud F. (2019). Servant Leadership Impact on Organizational Performance: The Mediating Role of Employee Engagement. International Journal of Human Resources Studies, 9(3): 85-100.

Ali U, Waqar S. (2013). Teachers' Organizational Citizenship Behavior Working Under Different Leadership
Styles. Pakistan Journal of Psychological Research, 28(2): 297316.

Altuntas S, Baykal U. (2010). Relationship Between Nurses' Organizational Trust Levels And Their Organizational Citizenship Behaviors. Journal of Nursing Scholarship, 42(2): 186-194. https://doi.org/10.1111/j.15475069.2010.01347.x.

Angelov, B, Zekiri J. (2011). Measuring Customer Satisfaction with Service Quality Using American Customer Satisfaction Model (ACSI Model). International Journal of Academic Research in Business and Social Sciences, 1(3): 236-258.

Arain G, Hameed I, Crawshaw J. (2019). Servant Leadership and Follower Voice: The Roles of Follower Felt Responsibility for Constructive Change and Avoidance-Approach Motivation. European Journal of Work and Organizational Psychology, 28(4): 555-565.

Azizah N, Livikacansera S. (2016). Mengenal Generasi Millenial, Kementerian Komunikasi dan Informatika. Retrieved February 26, 2020,from

https://www.kominfo.go.id/content/d etail/8566/mengenal-generasimillennial.

Bao Y, Li C, \& Zhao H. (2018). Servant Leadership and Engagement: A Dual Mediation Model. Journal of Managerial Psychology, 33(6): 406417.

Barbuto Jr J, Gottfredson R. (2016). Human Capital, The Millennial's Reign, and The Need for Servant Leadership. Journal of Leadership Studies, 10(2): 59-63.

Bell E (2015). Understanding African American Males' Schooling 
Experiences: A Qualitative Inquiry Understanding African American Males' Schooling Experiences: A, 20(8): 1260-1269.

Bosscher I C. (2013). My How Things Have Changed! Strategic Organization Development and the Transformation of Human Resource Management My How Things Have Changed! Strategic Organization Development, 18(20): 1-5.

Brander R A, Patterson M, Chan Y E. (2012). The Qualitative Report Fostering Change in Organizational Culture Using a Critical Ethnographic Approach Fostering Change in Organizational Culture Using a Critical Ethnographic Approach. The Qualitative Report, 17(45): 1-27. Retrieved from http://nsuworks.nova.edu/tqr\%5Cn http://nsuworks.nova.edu/tqr/vol17/is s $45 / 2$.

Brewer C. (2010). Servant Leadership: A Review of Literature. Online Journal of Workforce Education and Development, 4(2): 3 .

Carlyle E. (2008). Organizational Cultural Design Factors Leading to Positive Behavior Changes Among Employees. https://doi.org/UMI : 3257958.

Chandaruba S. (2019). The Prospects and Challenges of Adopting ServantLeadership Philosophy in a Tanzania Public Leadership Context. Journal of Public Administration and Governance, 9(1): 168-190.

Charles D. (2015). Effects of Servant Leadership on Satisfaction with Leaders: Inclusion of Situational Variables. Emerging Leadership Journeys, 8(1): 46-61.

Choi S Y. (2014). The Effects of Leadership on Social Workers' Organizational Commitment: Focusing on Ethical
Leadership, Organizational Trust, and Supervisor Trust. Information, 17(10(A)): 4771-4778.

Chullen C L, Dunford B B, Angermeier I, Boss R W, Boss A D. (2010). Minimizing Deviant Behavior In Healthcare Organizations: The Affects Of Supportive Leadership And Job Design. Journal of Healthcare Management, 55(240): 381-397.

Corinna A, Cahyono E. (2019). Pola Perilaku Konsumsi Generasi Millenial Terhadap Produk Fashion Perspektif Monzer Kahf: Studi Kasus Mahasiswi Universitas Airlangga. Jurnal Ekonomi Syariah Teori dan Terapan, 6(2): 319-330.

Cullen K W, Baranowski T, Baranowski J, Hebert D, DeMoor C, Hearn M D, Resnicow K. (1999). Influence of School Organizational Characteristics on the Outcomes of a School Health Promotion Program. Journal of School Health, 69(9): 376-380.

https://doi.org/10.1111/j.17461561.1 999.tb06433.x.

Dillard J P, Hale J L, \& Segrin C. (1994). Close Relationships in Task Environments: Perceptions of Relational Types, Illicitness, and Power. Management Communication Quarterly, 7(3): 227 255.https://doi.org/10.1177/0893318 994007003001 .

Egbert M D, Pérez-Mercader J. (2016). Adapting to Adaptations: Behavioural Strategies that are Robust to Mutations and Other Organisational-Transformations.

Scientific Reports, 6(January): 1-10. https://doi.org/10.1038/srep18963.

Eva N, Robin M, Sendjaya S, van Dierendonck D, Liden R C. (2019). Servant Leadership: A Systematic 
Review and Call for Future Research. The Leadership Quarterly, 30(1): 111- 132.

Erkutlu H. (2011). The Moderating Role Of Organizational Culture In The Relationship Between Organizational Justice And Organizational Citizenship Behaviors. Leadership \& Organization Development Journal, 32(6):

532-554. https://doi.org/10.1108/01437731111 $\underline{161058}$.

Farrington S, Lillah R. (2019). Servant Leadership and Job Satisfaction Within Private Healthcare Practices. Leadership in Health Services, 32(1): 148-168.

Fecikova I. (2004). An Index Method for Measurement of Customer Satisfaction. The TQM Magazine, 16(1): 57-66.

Gong B, Greenwood R, Hoyte D, Ramkissoon A, He X. (2018). Millennials and Organizational Citizenship Behavior: The Role of Job Crafting and Career Anchor on Service. Management Research Review, 41(7): 774-788.

Gunawan A, Iqbal. (2018). Quality Measurement Customer Satisfaction Index (CSI) Method and ImportancePerforming Analysis (IPA) Diagram PT. ASDP Indonesia Ferry (Persero) Merak Banten. Journal of Engineering and Management in Industrial System, 6(1):11-19.

Heathfield S. (2019). How to Foster Employee Satisfaction. Retrieved February 20, 2020, from https://www.thebalancecareers.com/e mployee-satisfaction-1918014.

Huey Yiing L, Zaman Bin Ahmad K. (2009). The Moderating Effects Of Organizational Culture On The Relationships Between Leadership Behaviour And Organizational
Commitment And Between Organizational Commitment And Job Satisfaction And Performance. Leadership \& Organization Development Journal, 30(1): 53-86. https://doi.org/10.1108/01437730910 927106.

Huffman J B. (2015). Organizational Behavior : Perceptions Analysis Of Micro And Macro Organizational Behavior In An Organizational Setting Joshua T . Delich , B . A ., Me . D . Dissertation Prepared For The Degree Of Doctor Of Philosophy December 2015 Approved : Don Powell ,.

Kamani S M H, Namdari K. (2012). A Study Of The Relationship Between Organizational Justice And Support And Organizational Citizenship Behavior. International Journal of Arts and Sciences, 5(6): 355-368.

Khan M L, Salleh R, Hemdi M A B (2016). Effect Of Protean Career Attitudes On Organizational Commitment Of Employees With Moderating Role Of Organizational Career Management. International Review of Management and Marketing, 6(4): 155-160. Retrieved from https://www.scopus.com/inward/reco rd.uri?eid=2-s2.084969913395\&partnerID $=40 \& \mathrm{md} 5=$ 8a269a1e5ec72ebfb9c968ea7594626 d.

Koçak S, Burgaz B (2017). The Role of Leader Empowering Behaviours in Psychological Contract at High Schools. TeEğit im VBil im , 42(191): 351-370.

https://doi.org/10.15390/EB.2017.71 01 .

Lambert E G, Hogan N L, Dial K C, Altheimer I, Barton-Bellessa S M (2012). Examining The Effects Of Stressors On Organizational Citizenship Behaviors Among 
Private Correctional Staff: A Preliminary Study. Security Journal, 25(2): 152-172. https://doi.org/10.1057/sj.2011.16

Lambert S J. (2000). Added Benefits : the Link Between Work-Life Binefits and Organizational Citizenship Behavior. Academy of Management Journal, 43(5): 801-816. https://doi.org/10.2307/1556411.

Lanterman J. (2013). Officers' Job Satisfaction. In K. Peak (Ed.): Encyclopedia of Community Policing and Problem Solving. Thousand Oaks: SAGE Publications, Ltd.

Leslie J, Palmisano K. (2014). The Leadership Challenge in the Pharmaceutical Sector What Critical Capabilities are Missing in Leadership Talent and How Can They be Developed? Retrieved February 20, 2020, from Center for Creative Leadership: https://www.ccl.org/wpcontent/uploads/2016/09/leadershipchallenge-pharmaceutical-center-forcreative- leadership.pdf.

Liden R, Wayne S, Liao C, Meuser J. (2014). Servant Leadership and Serving Culture: Influence on Individual and Unit Performance. Academy of Management Journal, 57(5): 1434-1452.

Lieberman E A. (2006). What' S Fair Is Fair, Or Is It? The Effects Of MeritRelated Managerial Behaviors And Organizational Policies On Organizational Justice Perceptions By Eric A . Lieberman A Dissertation Submitted To The Graduate Faculty In Psychology In Partial Fulfillm.

Limbos M A P, Casteel C. (2008). Schools And Neighborhoods: Organizational And Environmental Factors
Associated With Crime In Secondary Schools. Journal of School Health, 78(10):

539-544.

https://doi.org/10.1111/j.1746-

1561.2008.00341.x .

Long S. (2017). Exploring Which Leadership Styles are Effective with Millennial Employees. Walden Dissertations and Doctoral Studies Collection.

Lu Y, Bugenhagen M J, Carvan M K, Ed D, Reed J G, Ph, D. (2010). The Relationship Between Leaders , Behaviors \& Organizational Learning Actions By A Dissertation Submitted In Partial Fulfillment Of The Requirements For The Degree Of Doctor Of Philosophy Specialization : Leadership Studies Under The Supervision Of Fond, (August).

Mangi A. (n.d.). Significance of Power and Politics : Its Influence on Organizational Behavior Towards Efficacy, 41(1968): 221-229.

Mc Cann J, Graves D, Cox L. (2014). Servant Leadership, Employee Satisfaction an Organizational Performance in Rural Community Hospitals. International Journal of Business and Management, 9(10): 28.

Melchar D, Bosco S. (2010). Achieving High Organization Performance through Servant Leadership. The Journal of Business Inquiry, 9(1): 74-88.

Mogotsi I C, Boon J A, Fletcher L. (2011). Modelling The Relationships Between Knowledge Sharing, Organisational Citizenship, Job Satisfaction And Organisational Commitment Among School Teachers In Botswana. African Journal of Library Archives and Information Science, 21(1): 41-58. 
https://doi.org/10.1017/CBO9781107 415324.004

Myrsiades L S. (1987). Corporate Stories as Cultural Communications in the Organizational Setting. Management Communication Quarterly, 1(1): 84120.

https://doi.org/10.1177/08933189870 01001005

Nawalkha A. (2018). The Rise of The Millennial, And Why They're Changing Work for The Better. Retrieved February 26, 2020, from Forbes Coaches Council: https://www.forbes.com/sites/forbesc oachescouncil/2018/11/08/the-riseof-the-millennial- and-why-theyrechanging-work-for-thebetter/\#1 aee26125e12

Padgett J, Gossett K, Mayer R, Chien W-W, Turner F. (2017). Improving Patient Safety through High Reliability Organizations. Qualitative Report, 22(2): 410-425. Preedy, V. (2010). 5-Point Likert Scale. In W. R.R (Ed.), Handbook of Disease Burdens and Quality of Life Measures. New York: Springer. Ragnarsson, S., Krisjansdottir, E., \& Gunnarsdottir, S. (2018). To Be Accountable While Showing Care: The Lived Experience of People in a Servant Leadership Organization. SAGE Open, 1(12): 1-12.

Sakeru A, Hermawan A, Triyonggo Y. (2019). Pengaruh Employee Engagement, Pemberdayaan, dan Komitmen Organisasi Terhadap Kinerja Karyawan PT. Toyota Motormanufacturing Indonesia. Jurnal Manajemen Teori dan Terapan, 12(2): 126-148.

Savage-Austin, Honeycutt A. (2011). Servant Leadership: A Phenomenological Study of Practices, Experiences, Organizational Effectiveness, and
Barriers. Journal of Business \& Economic Research, 9(1): 126-148.

Setyaningrum R P. (2017). Relationship Between Servant Leadership In Organizational Culture, Organizational Commitment, Organizational Citizenship Behaviour And Customer Satisfaction. European Research Studies Journal, 20(3): 554-569. Retrieved from https://www.scopus.com/inward/reco rd.uri?eid=2-s2.085028028298\&partnerID $=40 \& \mathrm{md} 5=$ 3cb8423750e59ad03660ad8bb0fbf30 0 .

Shang H, Huang P, Guo,Y. (2010). Managerial cognition: the sources of sustainable competitive advantage in hypercompetition. Nankai Business Review International, 1(4): 444-459. https://doi.org/10.1108/20408741011 082589 .

Shanker M. (2016). Organizational Citizenship Behavior and Organizational, 11(2): 397-408.

Somech, Anit: Drach-Zahavy, A. (2004). Exploring Organizational Citizenship Behaviour From An Organizational. Journal of Occupational and Organizational Psychology, 77, 281298.

Wilbon A. (1997). Organizational and Developmental Dynamics of Project Review Teams in Technology Environment. The Qualitative Report, 3(3): 1-20. Retrieved from http://nsuworks.nova.edu/tqr/vol3/iss 3/3\% 5Cnhttp://nsuworks.nova.edu/tq $\mathrm{r} / \mathrm{vol} 3 /$ is

s3/3/?utm_source=nsuworks.nova.ed u\%2Ftqr\%2Fvol3\%2Fiss3\%2F3\&ut $\mathrm{m} \_$medium $=\mathrm{P}$

DF\&utm_campaign=PDFCoverPage s. 
Situmorang S, Sarjono H. (2012). The Influence of Work's Motivation and Compensation Effect Towards Employee Satisfaction, and The Impact on The Work Performance at State Employees Civil Sub Company, Kebun Jeruk, West Jakarta. Jurnal Manajemen Teori dan Terapan, 1(1): 45-55.

Wu W, Tang F, Dong X, Liu C. (2015). Different Identifications Cause Different Types Of Voice: A Role Identity Approach To The Relations Between Organizational Socialization And Voice. Asia Pacific Journal of Management, 32(1): 251-287. https://doi.org/10.1007/s10490-0149384-x.

Yoon D, Jang J, Lee J (Jay). (2016). Environmental management strategy and organizational citizenship behaviors in the hotel industry. International Journal of Contemporary Hospitality Management, 28(8): 1577-1597. https://doi.org/10.1108/IJCHM-102014-0498. 